\title{
Association of the Serum Total Cholesterol to Triglyceride Ratio with Diabetic Retinopathy in Chinese Patients with Type 2 Diabetes: A Community-Based Study
}

Yifan Zhong · Song Yue · Jingyang Wu • Peng Guan · Guisen Zhang •

Lei Liu (iD) - Lei Chen

Received: December 1, 2018 / Published online: February 13, 2019

(C) The Author(s) 2019

\section{ABSTRACT}

Introduction: The relationship of total cholesterol (TC) or triglyceride (TG) to diabetic retinopathy (DR) has proven difficult to determine. In addition, there is no report of any study of the correlation between the TC/TG ratio and DR. This study was therefore undertaken to investigate the relationship between the TC/TG ratio and DR in Chinese adults with type 2 diabetes mellitus.

Methods: A community-based study was conducted from August to October 2014 in Fengyutan, Shenyang, China. DR was assessed based on the modified Airlie House classification of DR. Multivariable logistic regression models were used to evaluate the association

Enhanced Digital Features To view enhanced digital features for this article go to: https://doi.org/10.6084/ m9.figshare.7643117.

Y. Zhong · S. Yue $\cdot$ J. Wu $\cdot$ L. Liu ( $₫) \cdot$ L. Chen Department of Ophthalmology, The First Affiliated Hospital of China Medical University,

Shenyang 110001, China

e-mail: liuleijiao@163.com

P. Guan

Department of Epidemiology, School of Public

Health, China Medical University,

Taichung 110122, China

G. Zhang

Department of Ophthalmology, Hohhot Chao Ju Eye Hospital, Hohhot 010000, China between the TC/TG ratio and the presence of DR.

Results: Among the 420 diabetic participants in the study (157 men; mean (SD) age 61.7 (10.0) years), 76 (18.1\%) presented with DR. When the TC/TG ratio was analyzed categorically, participants with T2DM in tertile 2 (i.e., TC/TG 2.91-4.00) were more likely (OR 2.01; 95\% CI 1.01-3.99) to suffer from DR than patients in tertile 1 (i.e., $\mathrm{TC} / \mathrm{TG}<2.91$ ) in multivariable models. Similarly, participants in tertile 3 (TC/ TG > 4.00) were more likely (OR 2.59; 95\% CI $1.11-3.14 ; P=0.011)$ to suffer from DR than patients in tertile 1 . This association persisted when the TC/TG ratio was analyzed continuously $(P=0.014)$.

Conclusion: We found a novel positive association between TC/TG ratio and presence of DR in Chinese individuals with T2DM. Although longitudinal data are needed, this finding contributes to the accumulating evidence that a high TC/TG ratio may be implicated in DR.

Keywords: Diabetic retinopathy; Total cholesterol; Triglycerides; Type 2 diabetes mellitus

\section{INTRODUCTION}

Diabetic retinopathy (DR) is not only a very common complication of diabetes mellitus (DM) but also an important cause of vision loss 
and blindness in working-age adults [1, 2]. According to current scientific evidence, the pathogenesis of DR is still unclear, as it is complicated and related to many factors. Many previous studies have suggested that there is an association between abnormal lipid levels and the presence of DR [3-8]. In the Singapore Malay Eye study, a high total cholesterol (TC) level was found to protect against DR [9]. On the other hand, in another national survey performed in Korea by Yang et al., the serum TC level was not significantly associated with DR [10]. However, a cross-sectional study revealed that a higher triglyceride (TG) level was an independent risk factor for DR [11], although another cross-sectional study suggested that a lower TG level was associated with the presence of DR [12]. Hence, the relationship of TG or TC to DR is still unclear [13]. To date, no data on the correlation between the TC/TG ratio and DR have been reported.

In the study discussed in the present paper, we investigated the association of the TC/TG ratio with the presence of DR in a communitybased sample of Chinese patients with type 2 DM.

\section{METHODS}

\section{Study Population and Measurements}

The Shenyang Diabetes Eye Study is a community-based cross-sectional study of clinical, behavioral, genetic, and environmental factors related to DR in Northeast China. The methodology of the Shenyang Diabetes Eye Study has been detailed in previous publications [14]. Briefly, a total of 595 Chinese Han adults with type $2 \mathrm{DM}$ aged $\geq 18$ years were recruited from Fengyutan Street, Shenyang from August to October 2014 according to their health files at Fengyutan Health Center. The present study utilized data collected from a subset of participants for whom TC/TG ratio data were available (both TC and TG levels; $n=429$ ). Nine of those participants were subsequently excluded due to ungradable fundus images, leaving 420 participants available for analysis.
Each participant underwent a comprehensive assessment. Standardized interviews were done that covered the following information: age, gender, smoking, drinking, family history of DM, duration of DM, use of oral hypoglycemic agents, use of insulin, exercise, and history of high blood pressure (HBP). Height and weight were measured, and body mass index (BMI) was calculated using the following formula: $\mathrm{BMI}=$ weight $(\mathrm{kg}) /$ height $\left(\mathrm{m}^{2}\right)$. Systolic blood pressure (SBP), diastolic blood pressure (DBP), waist, and hips were then measured. The waist-to-hip ratio (WHR) was determined as the circumference of the waist divided by that of the hips. Fasting ( $\geq 8 \mathrm{~h}$ ) venous blood samples were obtained to measure fasting plasma glucose (FPG), hemoglobin $\mathrm{A}_{1 \mathrm{c}}\left(\mathrm{HbA}_{1 \mathrm{c}}\right)$, triglyceride (TG), and total cholesterol (TC) levels. All laboratory examinations were performed at the Endocrinology Laboratory, China Medical University, using commercially available assays. The TC/TG ratio was evaluated as the TC level divided by that of the TG level.

Diabetes mellitus (DM) was defined as FPG $\geq 7.0 \mathrm{mmol} / \mathrm{L}, \mathrm{HbA} 1 \mathrm{c} \geq 6.5 \%$, self-reported use of antidiabetic medication, or physician-diagnosed diabetes [15]. Hypertension was defined as a systolic $\mathrm{BP} \geq 140 \mathrm{mmHg}$ or diastolic $\mathrm{BP} \geq 90 \mathrm{mmHg}$ or any use of an antihypertensive medication. Smokers were defined as current smokers, regardless of the number of cigarettes they smoked per day. Drinkers were defined as those who reported that they drank at least five (for males) or four (for females) drinks at least once a week for one year.

After pupil dilation, the presence of DR was graded based on two-field (one centered on the optic disk; the other centered on the fovea) fundus photographs (CR6-45NM; Canon, Inc., Tokyo, Japan) according to the Early Treatment for Diabetic Retinopathy Study (ETDRS) standards [16]. This analysis of the fundus photographs wwas carried out in a blinded manner. DR was considered to be present if any characteristic lesion was present: microaneurysms, hemorrhages, cotton wool spots, intraretinal microvascular abnormalities, hard exudates, venous bleeding, or new vessels. Data from the worst eye were used in the analyses. This study was carried out in compliance with the Helsinki 
Declaration and approved by the ethics committee of the First Affiliated Hospital of China Medical University. All participants signed an informed consent form. The present study was a population-based investigation rather than clinical trial, so it was not registered.

\section{Statistical Analysis}

The Statistical Program for Social Sciences (SPSS, version 20.0, IBM) for Windows was used for statistical analysis. The mean \pm standard deviation (SD) was used to describe normally distributed data, while the median (interquartile range, IQR) was used if the data were non-normally distributed. The chi-square test was used for categorical outcomes. The Wilcoxon-Mann-Whitney test or $t$ test was employed to compare the characteristics of the participants with and without DR according to the continuous data distribution. Subjects were classified into three groups according to TC, TG, and TC/TG ratio using specific threshold values (TC/TG: tertile $1,<2.91$; tertile 2, 2.91-4.00; and tertile $3,>4.00$; TC: tertile $1,<4.74$; tertile 2, 4.74-5.74; and tertile 3, > 5.74; TG: tertile 1 , $<1.69$; tertile 2, 1.69-2.20; and tertile 3, $>2.20$ ), respectively. Logistic regression models (model 1: adjusted for age and gender; model 2: adjusted for age, gender, duration of DM, use of insulin, use of oral hypoglycemic agents, DBP, WHR, and $\mathrm{HbA}_{1 \mathrm{c}}$ levels) were used to assess the associations of $\mathrm{TC}, \mathrm{TG}$, and the $\mathrm{TC} / \mathrm{TG}$ ratio with DR. For all tests, a $P$ value of less than 0.05 was considered to indicate statistical significance.

\section{RESULTS}

Among the 420 participants with type 2 DM included in this study, 76 (18.1\%) had DR. The characteristics of all the study participants are shown in Table 1. Compared with the participants who did not have DR, the patients with DR were more likely to be males with a longer diabetes duration, to more frequently use oral hypoglycemic agents and insulin, and to have higher diastolic $\mathrm{BP}, \mathrm{HbA}_{1 \mathrm{c}}$, and $\mathrm{TC} / \mathrm{TG}$ ratio values but smaller waist and WHR values.
The TC/TG ratio was assessed continuously (per SD change). In model 1 (after adjusting for age and gender), a higher TC/TG ratio was associated with the presence of DR (odds ratio, OR 1.51; 95\% confidence interval CI 1.19-1.91; $P=0.001$ ); see Table 2. In model 2 (after adjusting for potential confounders such as age, gender, duration of DM, use of insulin, use of oral hypoglycemic agents, DBP, WHR, and $\mathrm{HbA}_{1 \mathrm{c}}$ levels), a higher TC/TG ratio was still associated with an increased risk for DR (OR 1.39; 95\% CI 1.07-1.82; $P=0.014)$. When the TC/TG ratio was assessed categorically after adjusting for age and gender, the participants in tertile 3 (TC/TG $>4.00)$ were found to be more likely (OR 1.92; 95\% CI 1.05-3.49; $P=0.034$ ) to suffer from DR than the patients in tertile 1 (TC/ $\mathrm{TG}<2.91$ ). After adjusting for potential confounders (age, gender, duration of DM, use of insulin, use of oral hypoglycemic agents, DBP, WHR, and $\mathrm{HbA}_{1 \mathrm{c}}$ levels), participants in tertile 2 (TC/TG 2.91-4.00) were more likely (OR 2.01; 95\% CI 1.01-3.99; $P=0.048$ ) to suffer from DR than patients in tertile 1 (TC/TG $<2.91)$. Similarly, participants in tertile $3(\mathrm{TC} / \mathrm{TG}>4.00)$ were more likely (OR 2.59; 95\% CI 1.11-3.14; $P=0.011)$ to suffer from DR than patients in tertile 1 (TC/TG < 2.91).

In the present study, we also conducted additional analyses to confirm the associations of TC and TG with DR, respectively. In Tables 3 and 4 , after adjusting for age, gender, duration of DM, use of insulin, use of oral hypoglycemic agents, DBP, WHR, and $\mathrm{HbA}_{1 \mathrm{c}}$ levels, the logistic regression analysis showed that TC (OR 0.86; 95\% CI 0.65-1.13; $P=0.275$ ) and TG (OR 0.84; $95 \%$ CI $0.59-1.18 ; P=0.329)$ were nonsignificant risk factors for DR. These associations persisted when the TC and TG levels were analyzed categorically.

\section{DISCUSSION}

The relationship of TG or TC to DR has been difficult to determine [13]. Hence, we conducted this population-based cross-sectional study to reveal the association between the TC/ TG ratio and the risk of DR. The present study suggests that TC and TG levels are not 
Table 1 Basic characteristics of the study participants

\begin{tabular}{|c|c|c|c|c|}
\hline Variables & Overall $(n=420)$ & $\mathrm{DR}(n=76)$ & $\operatorname{NDR}(n=344)$ & $P$ value \\
\hline Age (years) & $61.7 \pm 10.0$ & $60.1 \pm 9.6$ & $62.0 \pm 10.0$ & 0.138 \\
\hline Gender (male, \%) & $157(37.4)$ & $36(47.4)$ & $121(35.2)$ & 0.051 \\
\hline Current smoker (yes, \%) & $87(20.7)$ & $14(18.4)$ & $73(21.2)$ & 0.642 \\
\hline Current drinker (yes, \%) & $38(9.0)$ & $6(7.9)$ & $32(9.3)$ & 0.827 \\
\hline Family history of DM (yes, \%) & $111(26.4)$ & $25(32.9)$ & $86(25.0)$ & 0.195 \\
\hline Duration of DM (years) & $4.0(0.1-9.0)$ & $14.8(10.0-20.0)$ & $7.0(3.0-13.0)$ & $<0.001$ \\
\hline HBP (yes, \%) & $202(48.1)$ & $43(56.6)$ & $159(46.2)$ & 0.128 \\
\hline Use of oral hypoglycemic agents (yes, \%) & $202(48.1)$ & $46(60.5)$ & $156(45.3)$ & 0.022 \\
\hline Use of insulin (yes, \%) & $77(18.3)$ & $28(36.8)$ & $49(14.2)$ & $<0.001$ \\
\hline Exercise (yes, \%) & $31(7.4)$ & $3(3.9)$ & $28(8.1)$ & 0.33 \\
\hline Height $(\mathrm{cm})$ & $163.0(160.0-170.0)$ & $163.5(159.3-172.0)$ & $162.5(160.0-170.0)$ & 0.705 \\
\hline Weight (kg) & $68.0(60.0-72.0)$ & $68.0(60.0-72.8)$ & $68.0(60.3-72.0)$ & 0.976 \\
\hline BMI $\left(\mathrm{kg} / \mathrm{m}^{2}\right)$ & $24.4(23.1-26.1)$ & $24.0(22.6-26.0)$ & $24.5(23.2-26.3)$ & 0.526 \\
\hline $\mathrm{SBP}(\mathrm{mmHg})$ & $135.0(130.0-145.0)$ & $140.0(130.0-145.0)$ & $135.0(130.0-145.0)$ & 0.497 \\
\hline $\mathrm{DBP}(\mathrm{mmHg})$ & $80.0(76.3-90.0)$ & $85.0(80.0-90.0)$ & $80.0(75.3-87.8)$ & 0.024 \\
\hline Waist $(\mathrm{cm})$ & $86.0(82.0-90.0)$ & $83.0(80.0-86.0)$ & $87.0(82.0-90.0)$ & $<0.001$ \\
\hline $\operatorname{Hip}(\mathrm{cm})$ & $98.0(90.3-105.0)$ & $98.0(92.0-105.0)$ & $98.0(90.0-106.0)$ & 0.972 \\
\hline WHR & $0.9(0.80-0.9)$ & $0.8(0.7-0.9)$ & $0.9(0.8-1.0)$ & 0.008 \\
\hline $\mathrm{FPG}(\mathrm{mmol} / \mathrm{L})$ & $6.8(5.8-8.6)$ & $7.3(6.2-9.2)$ & $6.7(5.8-8.3)$ & 0.171 \\
\hline $\mathrm{TG}(\mathrm{mmol} / \mathrm{L})$ & $1.7(1.3-2.2)$ & $1.4(1.0-2.0)$ & $1.7(1.3-2.2)$ & 0.054 \\
\hline $\mathrm{TC}(\mathrm{mmol} / \mathrm{L})$ & $4.7(4.4-5.7)$ & $4.5(4.4-5.4)$ & $4.9(4.4-5.6)$ & 0.057 \\
\hline $\mathrm{HbA}_{1 \mathrm{c}}(\%)$ & $6.8(6.2-8.0)$ & $7.8(6.2-9.2)$ & $6.7(6.1-7.7)$ & 0.004 \\
\hline TC/TG ratio & $2.9(2.1-4.0)$ & $3.3(2.2-4.6)$ & $2.8(2.1-4.0)$ & 0.016 \\
\hline
\end{tabular}

HBP high blood pressure, BMI body mass index, SBP systolic blood pressure, DBP diastolic blood pressure, $W H R$ waist-tohip ratio, $F P G$ fasting plasma glucose, $N D R$ patients without diabetic retinopathy, $D R$ patients with diabetic retinopathy, $D M$ diabetes mellitus, $H b A_{1 c}$ hemoglobin $\mathrm{A}_{1 c}, T G$ triglyceride, $T C$ total cholesterol

associated with DR, respectively, while the TC/ TG ratio is significantly associated with a high risk of DR.

The association between the TC/TG ratio and any measure of DR is yet to be reported in the literature. However, the TC/TG ratio was found to be increased in patients with metabolic disease [17-19]. The risk factors for metabolic disease, such as diabetes, hypertension, and dyslipidemia, all contribute to DR [20] and may partly explain this association.

No clear association between dyslipidemia and DR has been established, as studies have reported inconsistent findings regarding this association. TC was associated with DR prevalence in the Singapore Epidemiology of Eye Diseases Study (which included Malay, Indian, and Chinese patients) [21]. In other population- 
Table 2 Associations of the TC/TG ratio with diabetic retinopathy (DR)

\begin{tabular}{|c|c|c|c|c|c|c|}
\hline & \multirow[t]{2}{*}{$n$} & \multirow{2}{*}{$\begin{array}{l}\text { DR }(n, \\
\%)\end{array}$} & \multicolumn{2}{|l|}{ Model $1^{a}$} & \multicolumn{2}{|l|}{ Model $2^{b}$} \\
\hline & & & $\overline{\text { OR }(95 \% \mathrm{CI})}$ & $P$ value & $\overline{\text { OR }(95 \% \mathrm{CI})}$ & $P$ value \\
\hline \multicolumn{7}{|l|}{$\mathrm{TC} / \mathrm{TG}$} \\
\hline Tertile 1 , TC/TG $<2.91$ & 212 & $29(13.7)$ & 1 & - & 1 & - \\
\hline $\begin{array}{l}\text { Tertile } 2, \mathrm{TC} / \mathrm{TG} \\
2.91-4.00\end{array}$ & 104 & $22(21.2)$ & $\begin{array}{l}1.68 \\
\quad(0.91-3.12)\end{array}$ & 0.098 & $\begin{array}{l}2.01 \\
\quad(1.01-3.99)\end{array}$ & 0.048 \\
\hline \multirow[t]{2}{*}{ Tertile $3, \mathrm{TC} / \mathrm{TG}>4.00$} & 104 & $25(24.0)$ & $\begin{array}{l}1.92 \\
\quad(1.05-3.49)\end{array}$ & 0.034 & $\begin{array}{l}2.59 \\
\quad(1.11-3.14)\end{array}$ & 0.011 \\
\hline & & & & $\begin{array}{l}P \text { for } \\
\quad \text { trend }=0.027\end{array}$ & & $\begin{array}{l}P \text { for } \\
\quad \text { trend }=0.123\end{array}$ \\
\hline Per SD increase in $\mathrm{TC} / \mathrm{TG}$ & 420 & $76(18.1)$ & $\begin{array}{l}1.51 \\
\quad(1.19-1.91)\end{array}$ & 0.001 & $\begin{array}{l}1.39 \\
\quad(1.07-1.82)\end{array}$ & 0.014 \\
\hline
\end{tabular}

adjusted for age and gender

b Adjusted for age, gender, duration of DM, use of insulin, use of oral hypoglycemic agents, DBP, WHR, and HbA $1 \mathrm{c}$ levels

Table 3 Associations of TC with diabetic retinopathy (DR)

\begin{tabular}{|c|c|c|c|c|c|c|}
\hline & \multirow[t]{2}{*}{$n$} & \multirow[t]{2}{*}{$\operatorname{DR}(n, \%)$} & \multicolumn{2}{|l|}{ Model $1^{a}$} & \multicolumn{2}{|l|}{ Model $2^{b}$} \\
\hline & & & OR $(95 \% \mathrm{CI})$ & $P$ value & OR (95\% CI) & $P$ value \\
\hline \multicolumn{7}{|l|}{$\mathrm{TC}$} \\
\hline Tertile $1, \mathrm{TC}<4.74$ & 211 & $46(21.8)$ & 1 & - & 1 & - \\
\hline $\begin{array}{l}\text { Tertile 2, TC } \\
4.74-5.74\end{array}$ & 104 & $14(13.5)$ & $\begin{array}{l}0.54 \\
\quad(0.28-1.05)\end{array}$ & 0.070 & $\begin{array}{l}0.53 \\
\quad(0.26-1.09)\end{array}$ & 0.084 \\
\hline \multirow[t]{2}{*}{ Tertile $3, \mathrm{TC}>5.74$} & 105 & $16(15.2)$ & $\begin{array}{l}0.67 \\
\quad(0.34-1.25)\end{array}$ & 0.206 & $\begin{array}{l}0.57 \\
\quad(0.28-1.17)\end{array}$ & 0.126 \\
\hline & & & & $\begin{array}{l}P \text { for trend } \\
\quad=0.119\end{array}$ & & $\begin{array}{l}P \text { for trend } \\
\quad=0.078\end{array}$ \\
\hline Per SD increase in $\mathrm{TC}$ & 420 & $76(18.1)$ & $\begin{array}{l}0.91 \\
\quad(0.71-1.17)\end{array}$ & 0.471 & $\begin{array}{l}0.86 \\
\quad(0.65-1.13)\end{array}$ & 0.275 \\
\hline
\end{tabular}

a Adjusted for age and gender

b Adjusted for age, gender, duration of DM, use of insulin, use of oral hypoglycemic agents, DBP, WHR, and HbA ${ }_{1 c}$ levels

based studies (the Beijing Eye Study and the 2008-2009 Korea National Health and Nutrition Examination Survey), dyslipidemia (both TC and TG levels) was not significantly associated with DR prevalence $[10,22]$. Our group previously reported that there was no association between TC and DR prevalence [23]. Similarly, in the current study, there was no significant association between hyperlipidemia (TC and TG) and risk of DR (Tables 3, 4). Even with inconsistent findings regarding the association of dyslipidemia (TC and TG levels and the TC/TG ratio) with DR, it is still important for clinicians to encourage patients to optimize their lipid profiles due to their associations with the risk of other complications of diabetes as 
Table 4 Associations of TG with diabetic retinopathy (DR)

\begin{tabular}{|c|c|c|c|c|c|c|}
\hline & \multirow[t]{2}{*}{$n$} & \multirow[t]{2}{*}{$\operatorname{DR}(n, \%)$} & \multicolumn{2}{|l|}{ Model $1^{a}$} & \multicolumn{2}{|l|}{ Model $2^{b}$} \\
\hline & & & $\overline{\text { OR }(95 \% \mathrm{CI})}$ & $P$ value & $\overline{\text { OR }(95 \% \mathrm{CI})}$ & $P$ value \\
\hline \multicolumn{7}{|l|}{ TG } \\
\hline Tertile 1, TG $<1.69$ & 215 & $47(21.9)$ & 1 & - & 1 & - \\
\hline $\begin{array}{l}\text { Tertile 2, TG } \\
1.69-2.20\end{array}$ & 102 & $15(14.7)$ & $\begin{array}{l}0.60 \\
\quad(0.32-1.15)\end{array}$ & 0.123 & $\begin{array}{l}0.61 \\
\quad(0.29-1.23)\end{array}$ & 0.165 \\
\hline \multirow[t]{2}{*}{ Tertile 3 , TG $>2.20$} & 103 & $14(13.6)$ & $\begin{array}{l}0.57 \\
\quad(0.29-1.11)\end{array}$ & 0.097 & $\begin{array}{l}0.57 \\
\quad(0.27-1.18)\end{array}$ & 0.128 \\
\hline & & & & $\begin{array}{l}P \text { for trend } \\
\quad=0.061\end{array}$ & & $\begin{array}{l}P \text { for trend } \\
\quad=0.087\end{array}$ \\
\hline Per SD increase in TG & 420 & $76(18.1)$ & $\begin{array}{l}0.82 \\
\quad(0.59-1.12)\end{array}$ & 0.211 & $\begin{array}{l}0.84 \\
\quad(0.59-1.18)\end{array}$ & 0.329 \\
\hline
\end{tabular}

${ }^{a}$ Adjusted for age and gender

b Adjusted for age, gender, duration of DM, use of insulin, use of oral hypoglycemic agents, DBP, WHR, and $\mathrm{HbA}_{1 \mathrm{c}}$ levels

well as DR. The strengths of our study include the following: the association between the TC/ TG ratio and DR was adjusted for major potential confounders including age, gender, $\mathrm{HbA}_{1 \mathrm{c}}$, DBP, WHR, duration of DM, antidiabetic medication (such as oral hypoglycemic agents and insulin); it was the first investigation of an association between the TC/TG ratio and DR; and it used a population-based study design. However, potential limitations of our study should be mentioned. First, nearly $90.8 \%$ of the participants with diabetes had nonproliferative diabetic retinopathy (NPDR); subjects with proliferative changes were less common. This could have led to the underestimation of the association between the TC/TG ratio and the risk of PDR. Second, the association between the TC/TG ratio and DR was not adjusted for the effects of other potential confounders such as socioeconomic status and education, as the information required to adjust for these potential confounders was not collected. Third, twofield retinal photographs were used to evaluate and monitor for the presence of DR. This may have led to underestimation of the true prevalence of DR. Additionally, our study was a crosssectional investigation which primarily did not allow statements about longitudinal relationships. Hence, a longitudinal population-based study is needed to investigate the association between TC/TG ratio and risk of DR.

\section{CONCLUSION}

In summary, after adjusting for potential confounders, the TC/TG ratio in Chinese individuals with diabetes was found to be associated with DR events. This significant association may help us to better understand the risk of DR and may lead to new targeted therapy aimed at preventing DR.

\section{ACKNOWLEDGEMENTS}

The authors are grateful to the participants of this study for their invaluable contributions to this work.

Funding. This study was supported by the National Natural Science Foundation of China (grant no. 81300783) and the Science Foundation of Liaoning Provincial Department of Education (grant no. LQNK201703). The funders were not involved in the design and 
implementation of the study; the collection, management, analysis, and interpretation of the data; the preparation, review, or approval of the manuscript; the payment of the journal's article processing charges; or in the decision to submit the manuscript for publication. The article processing charges were funded by the authors.

Authorship. All named authors meet the International Committee of Medical Journal Editors (ICMJE) criteria for authorship for this article, take responsibility for the integrity of the work as a whole, and have given their approval for this version to be published.

Authorship Contributions. Lei Liu designed the study and reviewed the manuscript. Yifan Zhong, Song Yue, and Jingyang Wu collected data. Peng Guan, Guisen Zhang, Lei Liu, and Lei Chen analyzed the data and drafted the manuscript.

Disclosures. Yifan Zhong, Song Yue, Jingyang Wu, Peng Guan, Guisen Zhang, Lei Liu, and Lei Chen have nothing to disclose.

Compliance with Ethics Guidelines. All procedures performed in studies involving human participants were in accordance with the institutional review board of The First Affiliated Hospital of the China Medical University and with the 1964 Helsinki Declaration and its later amendments or comparable ethical standards. Informed consent was obtained from all individuals included in the study.

Data Availability. The datasets generated during and/or analyzed during the current study are available from the corresponding author on reasonable request.

Open Access. This article is distributed under the terms of the Creative Commons Attribution-NonCommercial 4.0 International License (http://creativecommons.org/licenses/ by-nc/4.0/), which permits any noncommercial use, distribution, and reproduction in any medium, provided you give appropriate credit to the original author(s) and the source, provide a link to the Creative Commons license, and indicate if changes were made.

\section{REFERENCES}

1. Kempen JH, O'Colmain BJ, Leske MC, Haffner SM, Klein R, Moss SE, Taylor HR, Hamman RF, Eye Diseases Prevalence Research Group. The prevalence of diabetic retinopathy among adults in the United States. Arch Ophthalmol. 2004;122(4):552-63.

2. Yamada M, Hiratsuka $\mathrm{Y}$, Roberts CB, Pezzullo ML, Yates K, Takano S, Miyake K, Taylor HR. Prevalence of visual impairment in the adult Japanese population by cause and severity and future projections. Ophthalmic Epidemiol. 2010;17(1):50-7.

3. Kostev K, Rathmann W. Diabetic retinopathy at diagnosis of type 2 diabetes in the UK: a database analysis. Diabetologia. 2013;56(1):109-11.

4. Fong DS, Aiello L, Gardner TW, King GL, Blankenship G, Cavallerano JD, Ferris FL 3rd, Klein R, American Diabetes Association. Diabetic retinopathy. Diabetes Care. 2003;26(1):226-9.

5. Yau JW, Rogers SL, Kawasaki R, Lamoureux EL, Kowalski JW, Bek T, Chen SJ, Dekker JM, Fletcher A, Grauslund J, et al. Global prevalence and major risk factors of diabetic retinopathy. Diabetes Care. 2012;35(3):556-64.

6. Chew EY, Klein ML, Ferris FL, 3rd, Remaley NA, Murphy RP, Chantry K, Hoogwerf BJ, Miller D. Association of elevated serum lipid levels with retinal hard exudate in diabetic retinopathy. Early Treatment Diabetic Retinopathy Study (ETDRS) Report 22. Arch Ophthalmol. 1996;114(9):1079-84.

7. Azad N, Bahn GD, Emanuele NV, Agrawal L, Ge L, Reda D, Klein R, Reaven PD, Hayward R, VADT Study Group. Association of blood glucose control and lipids with diabetic retinopathy in the Veterans Affairs Diabetes Trial (VADT). Diabetes Care. 2016;39(5):816-22.

8. Agroiya P, Philip R, Saran S, Gutch M, Tyagi R, Gupta KK. Association of serum lipids with diabetic retinopathy in type 2 diabetes. Indian J Endocrinol Metab. 2013;17(Suppl 1):S335-337.

9. Wong TY, Cheung N, Tay WT, Wang JJ, Aung T, Saw SM, Lim SC, Tai ES, Mitchell P. Prevalence and risk factors for diabetic retinopathy: the Singapore Malay Eye Study. Ophthalmology. 2008;115(11):1869-75. 
10. Yang JY, Kim NK, Lee YJ, Noh JH, Kim DJ, Ko KS, Rhee BD, Kim DJ. Prevalence and factors associated with diabetic retinopathy in a Korean adult population: the 2008-2009 Korea National Health and Nutrition Examination Survey. Diabetes Res Clin Pract. 2013;102(3):218-24.

11. Liu Y, Yang J, Tao L, Lv H, Jiang X, Zhang M, Li X. Risk factors of diabetic retinopathy and sightthreatening diabetic retinopathy: a cross-sectional study of 13473 patients with type 2 diabetes mellitus in mainland China. BMJ Open. 2017;7(9):e016280.

12. Zhang G, Chen H, Chen W, Zhang M. Prevalence and risk factors for diabetic retinopathy in China: a multi-hospital-based cross-sectional study. $\mathrm{Br} \mathrm{J}$ Ophthalmol. 2017;101(12):1591-5.

13. Wat N, Wong RL, Wong IY. Associations between diabetic retinopathy and systemic risk factors. Hong Kong Med J. 2016;22(6):589-99.

14. Liu L, Wu J, Yue S, Geng J, Lian J, Teng W, Huang D, Chen L. Incidence density and risk factors of diabetic retinopathy within type 2 diabetes: a five-year cohort study in China (Report 1). Int J Environ Res Public Health. 2015;12(7):7899-909.

15. American Diabetes Association. Standards of medical care in diabetes-2014. Diabetes Care. 2014;37(Suppl 1):S14-80.

16. Wong TY, Klein R, Islam FM, Cotch MF, Folsom AR, Klein BE, Sharrett AR, Shea S. Diabetic retinopathy in a multi-ethnic cohort in the United States. Am J Ophthalmol. 2006;141(3):446-55.

17. Cheng SH, Cheng CY, Sun NL. Lipid-lowering agents for dyslipidemia in patients who were infected with HIV in Taoyuan, Taiwan. J Int AIDS Soc. 2014;17(4 Suppl 3):19556.

18. Seo SM, Baek SH, Jeon HK, Kang SM, Kim DS, Kim WS, Kim HS, Rha SW, Park JS, Seong IW, et al. Correlations between the level of high-sensitivity C-reactive protein and cardiovascular risk factors in Korean adults with cardiovascular disease or diabetes mellitus: the CALLISTO study. J Atheroscler Thromb. 2013;20(7):616-22.

19. Yoshida A, Kouwaki M, Matsutani Y, Fukuchi Y, Naito M. Usefulness of serum total cholesterol/ triglyceride ratio for predicting the presence of small, dense LDL. J Atheroscler Thromb. 2004;11(4):215-9.

20. Chua J, Lim CXY, Wong TY, Sabanayagam C. Diabetic retinopathy in the Asia Pacific. Asia Pac J Ophthalmol. 2018;7(1):3-16.

21. Tan GS, Gan A, Sabanayagam C, Tham YC, Neelam $\mathrm{K}$, Mitchell P, Wang JJ, Lamoureux EL, Cheng CY, Wong TY. Ethnic differences in the prevalence and risk factors of diabetic retinopathy: the Singapore Epidemiology of Eye Diseases Study. Ophthalmology. 2018;125(4):529-36.

22. Wang S, Xu L, Jonas JB, You QS, Wang YX, Yang H. Dyslipidemia and eye diseases in the adult Chinese population: the Beijing eye study. PLoS One. 2012;7(3):e26871.

23. Hu Y, Teng W, Liu L, Chen K, Liu L, Hua R, Chen J, Zhou Y, Chen L. Prevalence and risk factors of diabetes and diabetic retinopathy in Liaoning province, China: a population-based cross-sectional study. PLoS One. 2015;10(3):e0121477. 